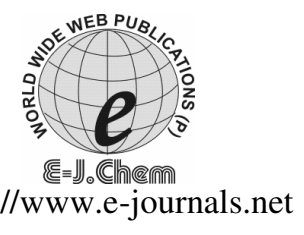

ISSN: 0973-4945; CODEN ECJHAO

E-Journal of Chemistry

Vol. 5, No.4, pp. 838-843, October 2008

\title{
Microelement Contents of Locally Produced and Imported Wheat Grains in Yemen
}

\author{
M. A. AL-GAHRI* and M. S. ALMUSSALI \\ ${ }^{*}$ Chemistry Department, College of Education/Aden. \\ Aden University, Yemen. \\ Food Research and Post Harvest Technology,Centre/Aden \\ Agricultural Research and Extension Authority/Dhmar, Yemen. \\ mohsen72@hotmail.com
}

Received 4 February 2008; Accepted 2 April 2008

\begin{abstract}
In the last few decades, wheat-based products have received considerable attention in view of their potential role in transporting of microelements into the human diet. In Yemen, bread is the staple food, produced in different kinds from local and imported wheat. Most of it is not subjected to microelemental analysis. The objective of this study is to determine quantitatively the microelement such as $\mathrm{Fe}, \mathrm{Cu}, \mathrm{Mn}, \mathrm{Zn}, \mathrm{Co}, \mathrm{Cd}$ and $\mathrm{Pb}$ in samples of wheat grains produced locally from different cultivated regions in Yemen as well as those imported from USA and Austria. Flame atomic absorption spectrophotometry was used for analysis. The results show that the contents of the microelements in the studied samples are generally within the permissible levels except cadmium. The samples collected from middle altitude and eastern plateau the cadmium is above the permissible level.
\end{abstract}

Keyword: Microelement, Wheat, Yemen, Spectrophotometeric analysis

\section{Introduction}

Metals have an impact on human health in many ways. Some elements such as $\mathrm{Cu}, \mathrm{Mn}$ and $\mathrm{Zn}$ are essential micronutrients with a human requirement of not more than a few milligrams per day. However, micronutrients may become harmful when their ingestion rates are too high. In contrast, trace elements such as $\mathrm{Cd}$ and $\mathrm{Pb}$ are well known as toxic if their intake through ingestion or inhalation is excessive. The deficiencies, excesses or imbalances in the supply of inorganic elements from dietary sources can have an important deleterious influence on human health ${ }^{1-2}$. The amount of element ingested by human is directly related to alimentary habits and their content in foodstuffs. 
In the last few decades, cereal products including wheat-based products have received considerable attention in view of their potential role in transporting of toxic microelements into the human diet. Since 1973, As, Cu, Cd, Fe, Hg, Pb, and $\mathrm{Zn}$ have been considered by the joint FAO/WHO Codex Alimentarius Commission to be potentially toxic for human diet with As (as arsenite) being carcinogenic ${ }^{3}$.

Bread is the staple food in Yemen that is produced in different kinds from wheat. In Yemen, the total cultivated area ranges from 1.1-1.8 million hectare depends upon sufficient rain fall. In the year 2004, the total cultivated area reached to 1.1 million hectare, cereals crops occupy $57.6 \%$ of it, from which $12.2 \%$ is occupied by wheat crop. The total cultivated area of wheat crop in the year 2004 is 83801 hectare, with a total production of 103265 tons of wheat grain. The quantities of wheat grain imported in 2004 is 1.806 .332 ton. This indicates that the self-sufficiency of wheat grains in Yemen ranges ${ }^{4}$ from 5.5 to $13.4 \%$

A survey ${ }^{5-9}$ of toxic elements in wheat grain has been carried out in a number of countries. The objective of this study is to determine quantitatively seven microelements such as $\mathrm{Cu}, \mathrm{Fe}, \mathrm{Pb}, \mathrm{Co}, \mathrm{Cd}, \mathrm{Mn}$, and $\mathrm{Zn}$ in wheat grain samples representing some different growing regions in Yemen, harvested in 2004 and two samples of imported wheat grains usually imported from USA and from Austria.

\section{Experimental}

\section{Sampling}

Wheat crop is mainly cultivated in the northern altitude constituting the governorates of Sana'a and Amran. The altitude of these areas is more than $2000 \mathrm{~m}$ above sea level. It is also grown in the middle altitudes that include the governorates of Dhmar and Albidah. The crop is irrigated in these areas by rain fall during summer season. Another wheat cultivated area in Yemen is the eastern plateau that represents governorates of Hadramout, Mareb and Aljouf. The crop is irrigated by tube wells. Samples of wheat grains were collected from different fields during the harvest period as mentioned by Bruggemann, Kumpulainen, and GEMS / Food-EURO ${ }^{10-12}$. Samples of the imported wheat grains were collected from Aden seaport using the quartering method.

\section{Microelements analysis}

Aliquots of the composite wheat grain samples were manually cleaned and milled in a hammer mill, having sieve of $0.5 \mathrm{~mm}$ to obtain fine whole meal flour. Flour was stored in clean polyethylene flasks at $5^{\circ} \mathrm{C}$. Sub-sample of fresh whole meal flour about $5 \mathrm{~g}$ on dry matter basis was dissolved in $10 \mathrm{~mL}$ of concentrated nitric acid and heated under reflux. Then, $10 \mathrm{~mL}$ of concentrated perchloric acid was added and heated until formation of nitrous fumes stopped. The digestion temperature did not exceed $85^{\circ} \mathrm{C}$. The solution was placed in a $50 \mathrm{~mL}$ volumetric flask and made up to the volume with deionised water. Samples were analyzed ${ }^{13}$ by flame atomic absorption spectrometer (FAAS) model VARIO - 6.

All metal concentrations were determined by direct aspiration of the aqueous solution into air-acetylene flame AAS. All chemicals used in the sample treatments were of ultra pure grade purchased from MRCK.

\section{Results and Discussion}

Generally, microelement concentrations in foodstuffs depend on soil characteristics, such as content of organic matter, $\mathrm{pH}$, and clay mineralogy, which can affect the bioavailability of elements. Besides environmental pollution, a matter of concern is the addition of chemical 
products such as fertilizers, fungicides, insecticides and herbicides to crops. On the other hand, wheat grains was mainly milled in the national millers with an extraction rate of about $76 \%$.The majority of minerals left in bran was lost during the milling. Table 1 shows the content of microelements in the studied representing wheat samples.

Table 1. Microelements content of the studied samples of wheat grain.

\begin{tabular}{cccccc}
\hline \multirow{2}{*}{ Ions } & \multicolumn{5}{c}{ Wheat grain samples (sources), $\mu \mathrm{g} / \mathrm{g}$} \\
\cline { 2 - 6 } & Northern altitude & Middle altitude & Eastern plateau & Austria & USA \\
\hline $\mathrm{Fe}$ & $51.40 \pm 0.11$ & $53.05 \pm 0.13$ & $51.06 \pm 0.13$ & $57.63 \pm 0.12$ & $60.54 \pm 0.09$ \\
$\mathrm{Zn}$ & $10.05 \pm 0.12$ & $16.60 \pm 0.14$ & $16.96 \pm 0.09$ & $11.55 \pm 0.13$ & $17.13 \pm 0.12$ \\
$\mathrm{Mn}$ & $35.43 \pm 0.07$ & $49.82 \pm 0.04$ & $34.88 \pm 0.06$ & $44.10 \pm 0.07$ & $41.33 \pm 0.09$ \\
$\mathrm{Cu}$ & $8.30 \pm 0.01$ & $9.02 \pm 0.02$ & $5.73 \pm 0.02$ & $4.70 \pm 0.03$ & $5.24 \pm 0.02$ \\
$\mathrm{Co}$ & $\mathrm{ND}$ & $0.177 \pm 0.001$ & $0.071 \pm 0.003$ & $0.043 \pm 0.001$ & $0.154 \pm 0.002$ \\
$\mathrm{Cd}$ & $\mathrm{ND}$ & $0.246 \pm 0.001$ & $0.296 \pm 0.002$ & $\mathrm{ND}$ & $0.117 \pm 0.001$ \\
$\mathrm{~Pb}$ & $0.257 \pm 0.01$ & $0.367 \pm 0.02$ & $\mathrm{ND}$ & $\mathrm{ND}$ & $0.346 \pm 0.01$ \\
\hline
\end{tabular}

$N D=$ Not detected

Iron $(\mathrm{Fe})$

From the results shown in Table 1, the content of iron in the local wheat samples ranges from 51 to $53 \mu \mathrm{g} / \mathrm{g}$. This content is near to the normal iron content in wheat $46 \mu \mathrm{g} / \mathrm{g}$ as stated by Kent ${ }^{14}$, but the content in the imported samples ranges from 57.60 to $60.0 \mu \mathrm{g} / \mathrm{g}$. These contents were to some extent, higher than the normal content if compared to the local samples. Still both of those contents are considered low if compared with the study of Biljana and Antonija, different representative samples of wheat grown in different growing areas in Serbia into which the content of iron ranged from 51.7 to $165 \mu \mathrm{g} / \mathrm{g}$, with a mean content ${ }^{15}$ of $807 \mu \mathrm{g} / \mathrm{g}$. On the other hand, the imported grains of wheat was mainly milled in the national millers, with an extraction rate of $76 \%$.The majority of minerals left in bran was lost during the milling . Such situation forces the local authorities to issue a rule to fortify the white wheat flour with iron. According to a technical report from a local research work executed by Almussali et.al ${ }^{16}$, the iron content in the white wheat flour milled locally from imported wheat has $50 \mu \mathrm{g} / \mathrm{g}$. This level of iron content in flour may be due to fortification. Mohammed and Taha collected samples of wheat from different markets in Yemen and other Arab countries (Saudi Arabia, Egypt ,Oman, Dubai, and Australia) and found that the concentration of iron ranged from $1.5 \mu \mathrm{g} / \mathrm{g}$ in Egypt to $3.13 \mu \mathrm{g} / \mathrm{g}$ in Yemen'. Those researchers did not define the markets in Yemen and also they didn't know whether the samples were collected form the locally produced wheat or from the imported ones our results, as well as other different local studies are totally different from the results of Mohammed and Taha.

\section{Zinc $(\mathrm{Zn})$}

The normal content of zinc in wheat, according to Kent ${ }^{14}$ is $33 \mu \mathrm{g} / \mathrm{g}$. Table 1 indicates that the content of zinc in the local samples as well as imported one were 10.05 and $17.13 \mu \mathrm{g} / \mathrm{g}$, which was some what low. Based on the results of the study conducted by Claudia ${ }^{17}$, the determined microelements in wheat grown in different areas in Argentine, the content of zinc was 36.87 $\mu \mathrm{g} / \mathrm{g}$. Another study by Lavado ${ }^{18}$ in the same country, but in plateau away from the cities, concluded that the content of this element in wheat reached to $44.37 \mu \mathrm{g} / \mathrm{g}$. Another study by Nagel $^{19}$ in Germany, found that wheat grains contain $35.50 \mu \mathrm{g} / \mathrm{g}$ of Zinc. The researcher $\mathrm{Mingchu}^{20}$ found that wheat crop supplied with organic fertilizer has zinc content in its grains ranging from 23.89 to $30.62 \mu \mathrm{g} / \mathrm{g}$. 
It is clear, from the above foreign studies results that the content of zinc in wheat grains were higher, compared to its contents found in our study either for local or imported samples. Salama and Radwan from Egypt, collected wheat grains among some foodstuffs from the local market and determined the content of some heavy metals in them. They found that zinc content ${ }^{8}$ was about $12.02 \mu \mathrm{g} / \mathrm{g}$, which is around the content of zinc found in our study. This is an important indication concerning the level of this microelement especially in the imported wheat grains; make us report to the local authorities of this deficiency. We think that more studies are needed, mainly in the imported wheat grains from other countries, so that one can give a final recommendation for the fortification of these microelements in the white wheat flour. Zinc values are ordered as U.S.A > Eastern Plateau $>$ Middle Altitude $>$ Austria $>$ Northern .Altitude.

\section{Manganese $(\mathrm{Mn})$}

The normal value of manganese in wheat as stated by Kent ${ }^{14}$ is $40 \mu \mathrm{g} / \mathrm{g}$. The tabulated results stated in Table 1 show that the content of manganese in wheat samples from the northern altitude and eastern plateau were the same about $35 \mu \mathrm{g} / \mathrm{g}$. The manganese content in the imported samples were 41.33 and $44.10 \mu \mathrm{g} / \mathrm{g}$ respectively, which is nearly the same and also similar to the normal value. The samples collected from the middle altitude $(2000 \mathrm{~m}$ above sea level) had $49.82 \mu \mathrm{g} / \mathrm{g}$, which is some what higher in content compared to other samples. After all the content of this element either in the local or imported samples are considered of normal value. Keeping in mind that milling will reduce such contents to about more than $50 \%$. The results indicate that manganese concentration is in the order Middle Altitude $>$ Austria $>$ U.S.A $>$ Northern Altitude $>$ Eastern plateau.

\section{Copper $(\mathrm{Cu})$}

Table 1 shows that the content of copper in the imported wheat grains as well as in the local samples, collected from the eastern plateau, are $4.70,5.24 \mu \mathrm{g} / \mathrm{g}$ and $5.73 \mu \mathrm{g} / \mathrm{g}$ respectively, which is nearly the same. However the content of the same element in the northern and middle altitude samples were, $8.30 \mu \mathrm{g} / \mathrm{g}$ and $9.02 \mu \mathrm{g} / \mathrm{g}$, which is approximately double. A local study conducted by Kathem, found the content of $5 \mu \mathrm{g} / \mathrm{g}$ of copper in wheat samples collected from the eastern plateau which is agreement with our results $^{21}$. Other studies reported that the content ${ }^{15,18,19}$ of this element ranged from 5-11 $\mu \mathrm{g} / \mathrm{g}$. The normal value of this element is $6 \mu \mathrm{g} / \mathrm{g}$ as stated by Kent ${ }^{14}$. It is clear that the order of the content of copper in the samples is Middle Altitude $>$ Northern Altitude $>$ Eastern plateau $>$ U.S.A $>$ Austria.

\section{Cobalt (Co)}

The contents of cobalt in wheat grain samples collected from eastern plateau $(1500 \mathrm{~m}$ above sea level) as well as that imported samples from Austria, was of 0.043 and $0.071 \mu \mathrm{g} / \mathrm{g}$ respectively. This content is near to the normal content of cobalt in wheat $0.05 \mu \mathrm{g} / \mathrm{g}$, as stated by Kent ${ }^{14}$. While those wheat grain samples collected from the middle altitude and imported from the U.S.A were 0.154 and $0.177 \mu \mathrm{g} / \mathrm{g}$ respectively, which was approximately about three times higher when compared to the normal content. In the samples collected from the northern altitude, cobalt has not been detected. The researcher Lavado from Argentina conducted a study to determine the heavy metals in wheat grains cultivated in soil treated organically, did not detect this element in studied wheat grain samples ${ }^{18}$. 


\section{Cadmium $(C d)$}

Table 1 shows that the cadmium was not detected in the local wheat samples collected from the northern altitude as well as the imported sample from Austria. Its concentration in the samples collected from the middle altitude and eastern plateau were 0.246 and $0.294 \mu \mathrm{g} / \mathrm{g}$ respectively. These contents were more than twice of the content found in the imported samples from the U.S.A, which is $0.117 \mu \mathrm{g} / \mathrm{g}$.

The content of cadmium in the wheat samples collected from the middle altitude and the eastern plateau were $0.246 \mu \mathrm{g} / \mathrm{g}$. and $0.296 \mu \mathrm{g} / \mathrm{g}$ respectively. Cadmium content in wheat imported from the U.S.A. is similar to the study by Lavado ${ }^{18}$ on Argentina wheat grains.

But the researcher Nagel ${ }^{19}$ concluded in his study that the cadmium content was 0.08 $\mu \mathrm{g} / \mathrm{g}$, which is of low content compared to the content in the samples of our study. After Kent ${ }^{14}$ stated that the normal content of cadmium in wheat grains is $0.1 \mu \mathrm{g} / \mathrm{g}$, whereas Walker ${ }^{22}$ stated that the permissible limits for cadmium in all foodstuffs is $0.05 \mu \mathrm{g} / \mathrm{g}$. A local study ${ }^{8}$ in Egypt conducted to determine the cadmium in some foodstuffs and found that the content of this element in wheat grains is $0.131 \mu \mathrm{g} / \mathrm{g}$, which is nearly the same content in the sample imported from the U.S.A.

\section{Lead $(\mathrm{Pb})$}

The normal content ${ }^{14}$ of lead in wheat is $0.80 \mu \mathrm{g} / \mathrm{g}$. Also, Fergusion ${ }^{23}$ stated that the permissible level of lead in food is $0.75 \mu \mathrm{g} / \mathrm{g}$. From Table 1, it is clear that the content of lead in the northern altitude samples is $0.257 \mu \mathrm{g} / \mathrm{g}$ and in the middle altitude and those imported samples from the U.S.A. is $0.367 \mu \mathrm{g} / \mathrm{g}$. Lead has not been detected in the wheat samples collected from the eastern plateau and those imported from Austria. In the earlier report ${ }^{15,19}$ it is found that the content of this element in wheat is $0.0366 \mu \mathrm{g} / \mathrm{g}$ and $0.015 \mu \mathrm{g} / \mathrm{g}$, respectively. The content of this element in the samples of our study especially collected from middle altitude and those from the U.S.A agreed mostly with the earlier results ${ }^{15,8}$ of lead content was $0.398 \mu \mathrm{g} / \mathrm{g}$. After all, grains are subjected to milling to get white flour where the content of lead was reduced to about $50 \%$.

\section{Conclusions}

The results of this study provide valuable information about the microelement contents in wheat, the main substance of bread, and the staple food of Yemeni citizens. The results show that the contents of the micro-elements in local and imported studied wheat are generally below the permissible levels, except cadmium, of which its content in the samples collected from the middle altitude and the eastern plateau was above the permissible level. More attention should be taken through deep studies towards cadmium content in wheat grain in such regions. However, these results can also be used to test the chemical quality of other foodstuffs in order to evaluate the possible risk associated with their consumption by humans.

\section{References}

1 Abrahams P W, Science of the Total Environment, 2002, 291, 1-32.

2 WHO/IAEA/FAO, Trace elements in human nutrition and health, WHO, in collaboration with FAO and IAEA, Geneva,1996, ISBN 9241561734

3 Ybanez N Montero and R Critical Reviews in Food Science and Nutrition, 1996, 36, 299-320.

4 Agricultural statistic department, Ministry of agriculture and irrigation. Repulic of Yemen, 2004. 
5 Cubadda F, Baldini M, Carcea M, Pasqui L A, Raggi A and Stacchini P, Food Additives and Contaminants, 2001, 18, 778-787.

6 Nan Z, Zhao C, Li J, Chen F \& Sun W, Water, Air and Soil Pollution, 2002, 133, 205-213.

$7 \quad$ Skrbic ${ }^{\prime} \mathrm{B}, \mathrm{C}^{`}$ upic' $\mathrm{S}$ and Cvejanov J, Physiology, 2002, 12, 12-15.

8 Salama A K and Radwan M A, Emir J Agric Sci., 2005, 17, 34- 42

9 Mohamed A E and Taha G M, Arabian J Sci Eng., 2003, 28, 163-171.

10 Bruggemann $\mathbf{J}$ and Kumpulainen J, Zeitschrift fur Lebensmittel-Untersuchung undForschung, 1995, 201, 1-6.

11 Bruggemann $\mathbf{J}$ and Kumpulainen J, Zeitschrift fur Lebensmittel-Untersuchung undForschung, 1995, 201,7-11.

12 GEMS/Food-EURO, Reliable evaluation of low level contamination of food, Second workshop, Kulmbach, Germany, 26-27 May 1995.

13 Beauty R D, Concepts, Instrumentation and techniques in atomic absorption spectrophotometry, Perkin Elmer, Norwalth, U.S.A. 1988.

14 Kent N L and Everes A D, Technology of cereals: An Introduction for students of food science and agriculture, $4^{\text {th }}$ Ed. Pergamon press, New York. 1990

15 Biljana Skrbic and Antonija Onjia, Food Control, 2007, 18, 338 -345.

16 Al-Mussali M S, Basanbul F and Hassan D, Technical Report of Food Res Post harvest Tech Centre. Yemen, 2005.

17 Claudia A, Rauls Lavado, Porcelli and Roberto Avarez, Soil and Tillage Research, 2001, 62, 55-60.

18 Lavado R S, J Environ Manage, 2006, 80, 116-119.

19 Nagel H D and Schutz G, Criteria for building up a plan to reduce emissions to protect soils and assessment on the long time, Impacts of mamad input of pollutants on the functions of the soils, (Umweltbundesamt) Berlin, Germany, 1997.

20 Mingchu Zang D, Heaney E Solberg and Henriquiz B, Annual report, Agromony Unit, Edminton Region, Alberta, 1998.

21 Kathem A, Bazar S R, Third scientific symposium on the effect of production and processing techniques on the quality of bread .for the celebration of Arabic Bread Day, Hadramout -Mukalla Republic of Yemen, 2001.

22 Walker J M, Regulation by other Countries in Foods and the Human Environment, Proceeding, No.2 "Cadmium Accumulation in Australian Agriculture" National Symposium, Canberra, 1-2 March .1988, Australian Government Publishing Service, Canberra, 176-85.

23 Fergusson, The heavy elements: Chemistry, environmental impact and health effects. Pergamon Press, New York.1990. 


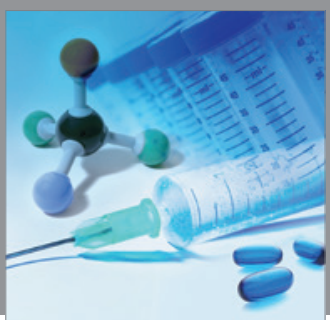

International Journal of

Medicinal Chemistry

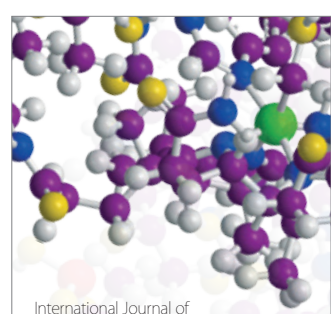

Carbohydrate Chemistry

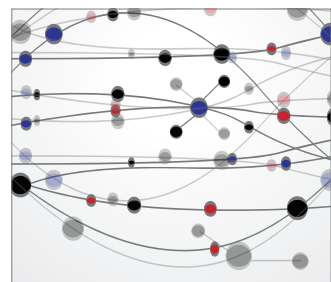

The Scientific World Journal
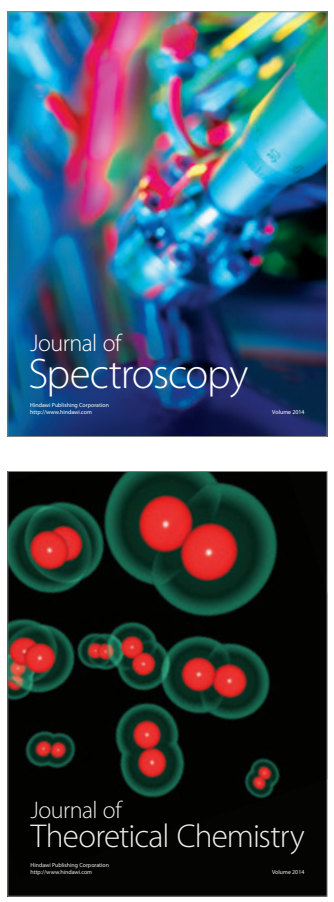
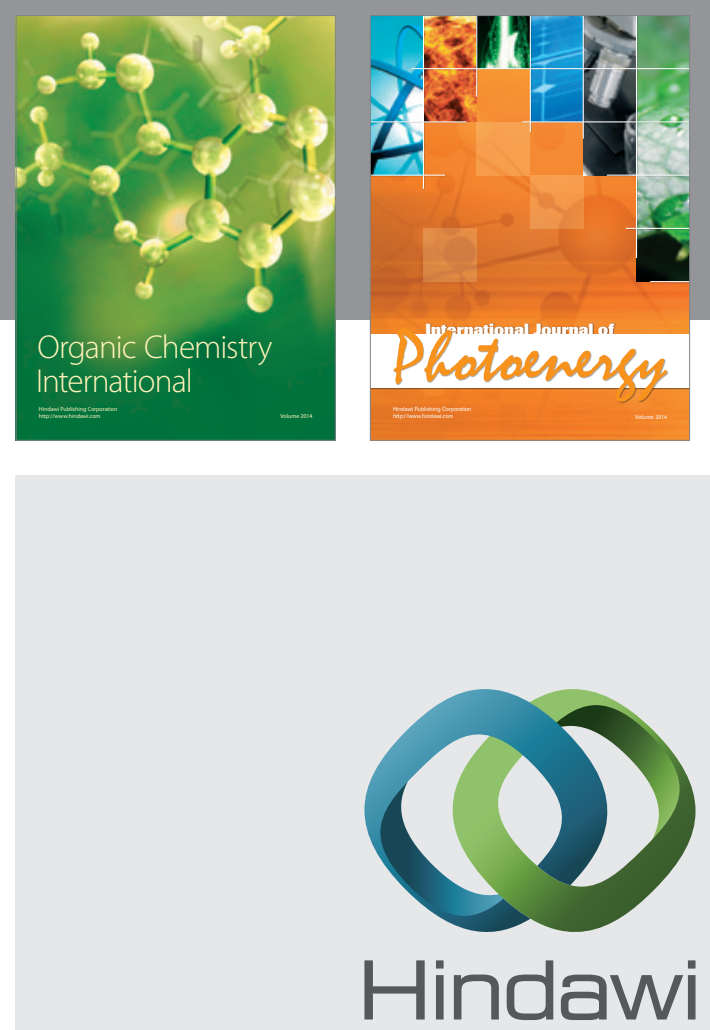

Submit your manuscripts at

http://www.hindawi.com
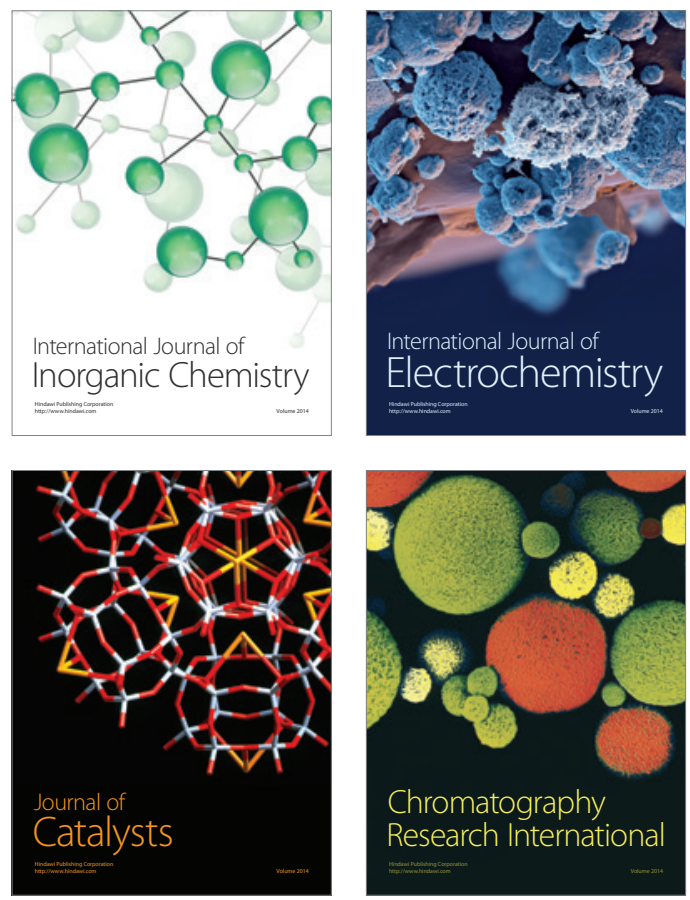
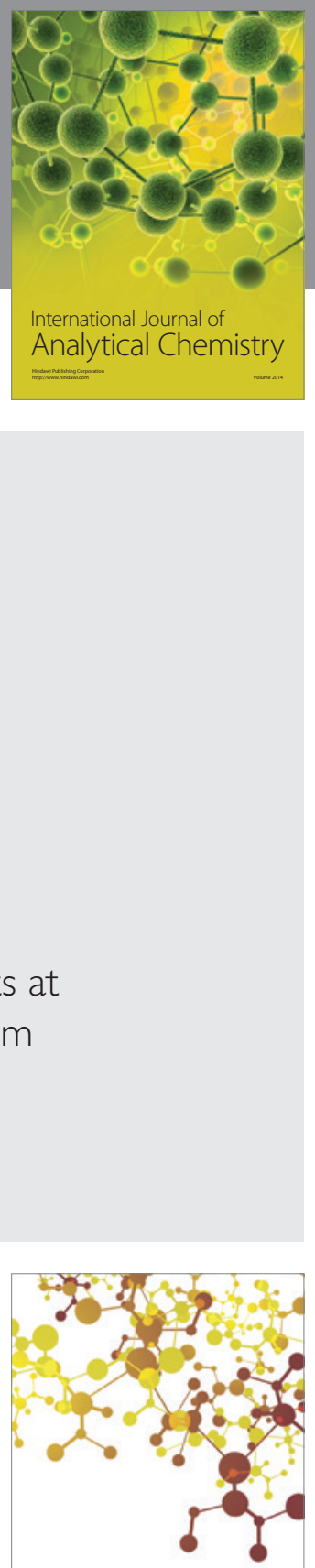

Journal of

Applied Chemistry
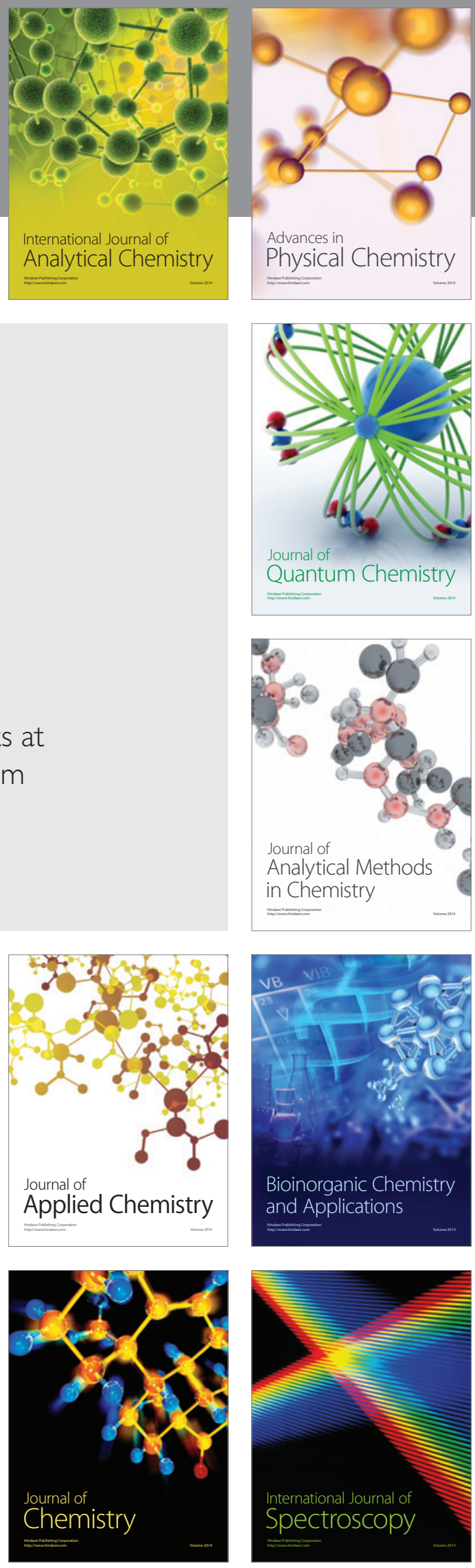